\title{
Percepções de licenciandos em Química sobre a Educação a Distância: reflexões e propostas
}

Natany Dayani de Souza Assai natanyassai@gmail.com

orcid. org/0000-0002-0851-9187

Universidade Estadual de Londrina (UEL), Londrina, PR, Brasil

Viviane Arrigo

viviane arrigo@hotmail.com

orcid.org/0000-0002-0638-3036

Universidade Estadual de Londrina (UEL), Londrina, PR, Brasil

Sergio de Mello Arruda sergioarruda@sercomtel.com.br

Universidade Estadual de Londrina (UEL),

Londrina, PR, Brasil

\section{RESUMO}

Este trabalho busca identificar as percepções de estudantes do curso de Licenciatura em Química sobre a Educação a distância (EaD) e explorá-las com o intuito de buscarmos propostas de formação que ofereçam subsídios para os futuros docentes trabalharem com esta modalidade. A coleta de dados se deu por meio de um questionário composto por 4 questões, respondidas por 5 estudantes do $8^{\circ}$ período. As respostas foram analisadas e interpretadas com base na Análise de Conteúdo, proposta por Moraes (1999). Os resultados demonstraram que estes estudantes, em fase de diplomação, apresentaram respostas divergentes a respeito das possibilidades da EaD, demonstrando alto índice de desconhecimento sobre a referida modalidade de ensino. Além disso, a maioria dos estudantes menciona que o ensino nesta modalidade só progrediu em função da evolução tecnológica que vem ocorrendo, entretanto, reconhecem as limitações da EaD para ensinar Química, devido à dificuldade que os alunos apresentam em relação a disciplina. Defendemos a importância de se trabalhar esse tema na formação inicial com a finalidade que os estudantes possam se embasar teoricamente a respeito das possibilidades da EaD. Além de integrar o tema as ementas das disciplinas de Prática de Ensino, propor aos estudantes o desenvolvimento de atividades embasadas nesta modalidade.

PALAVRAS-CHAVE: Educação a Distância. Formação Inicial. Química. Análise Textual. 


\section{INTRODUÇÃO}

A Educação a Distância (EaD) trata-se de uma modalidade de ensino que cresce exponencialmente em todas as instâncias educacionais, nos mais diversos cursos e disciplinas, na busca de acompanhar a sociedade contemporânea baseada em alicerces tecnológicos e na falta de tempo, conforme sugere Barbosa (2010).

Os principais motivos da atual expansão da $\mathrm{EaD}$, não só no país, mas em todo mundo, são basicamente três: 1) o aumento da demanda por formação ou qualificação; 2) a multiplicação de meios técnicos capazes de garantir materialmente a efetivação desse tipo de educação; e 3) a emergência de uma cultura que já não vê com muito estranhamento o estabelecimento de situações de interação envolvendo pessoas situadas em contextos locais distintos (BENAKOUCHE, 2000).

Esta modalidade tem atraído jovens e adultos por questões de viabilidade, como a possibilidade que o aluno tem de escolher o local e o horário apropriado para estudar. Logo, o ensino encontra-se centrado no aluno, uma vez que, o professor atua em um ambiente virtual, ou seja, professores e alunos ficam separados fisicamente, porém mediados pelas tecnologias de comunicação. Assim, ao abordar esse tema, há uma grande discussão em torno do ensino e aprendizagem envolvendo a $\mathrm{EaD}$, principalmente no que se refere a formação de professores de algumas Ciências, entre elas a Química.

A necessidade de qualificação profissional aliada às potencialidades ofertadas pelas tecnologias, principalmente a internet, aumentou a quantidade de pessoas que buscam na Educação a Distância uma oferta de ensino atemporal, seja para cursos rápidos, graduação ou pós-graduação.

Paulin e Miskulin (2015) ressaltam a relação existente entre a formação de professores e o processo de evolução e disseminação das Tecnologias de Informação e de Comunicação (TIC) na sociedade. A presença das tecnologias contribui permeia o processo formativo social, alterando hábitos, modificando a rotina da sala de aula e da ação docente, e consequentemente a formação docente pelo oferecimento de cursos a distância. Será que os professores e futuros professores percebem essas modificações e como funciona a Educação a Distância? Sabem sob quais pilares ela se sustenta?

Diante do exposto, nota-se a necessidade de se conhecer as percepções dos estudantes das licenciaturas sobre a atividade docente na modalidade EaD. Estas percepções, por sua vez, precisam ser discutidas e problematizadas no sentido da elaboração de propostas de $\mathrm{EaD}$ que atendam as demandas de ensino e aprendizagem em sala de aula. Portanto, busca-se com esta investigação responder a seguinte questão: Quais as percepções de estudantes do curso de licenciatura em Química a respeito da atividade docente na EaD?

Para isso, objetivamos nesta investigação identificar as percepções de estudantes do curso de Licenciatura em Química sobre a EaD e explorá-las com o intuito de buscarmos propostas de formação que ofereçam subsídios para os futuros docentes trabalharem com esta modalidade. 


\title{
APORTE TEÓRICO
}

A Educação a Distância vive um período de grandes mudanças. O avanço da internet está facilitando o acesso a cursos on-line, de graduação e pós-graduação, principalmente de especialização. Garcia e Gouw (2009) enfatizam que apesar dos movimentos que ocorreram em prol da Educação a Distância, foi a partir da Lei de Diretrizes e Bases da Educação (LDB) que ocorreu a democratização do acesso ao Ensino Superior. A Lei 9394/96 de Diretrizes e Bases da Educação (BRASIL, 1996), nos artigos 80 e 87, reconhecem a Educação a Distância nos diferentes níveis de ensino, permitindo o credenciamento de instituições e a autorização de cursos e de pesquisa acadêmica. A partir disso começam a surgir cursos de graduação e ocorre a expansão da educação a distância.

Contudo, apenas em 2005 o Ministério da Educação aprova e constitui a Educação a Distância como modalidade educacional, por meio do Decreto $n^{\circ} 5.622$ (BRASIL, 2005). No trecho a seguir Niskier (2010) retrata sobre a consolidação da EaD:

\begin{abstract}
A EAD tornou-se a modalidade fundamental de aprendizagem e ensino, no mundo inteiro. Antes cercada de mistério, hoje é até mesmo reivindicada por sindicatos poderosos, no Brasil, onde o seu prestígio cresce de forma bastante visível. Parte-se de um conceito extremamente simples: alunos e professores separados por uma certa distância e, as vezes pelo tempo. A modalidade modifica aquela velha ideia de que, para existir ensino, seria sempre necessário contar com a figura do professor em sala e de um grupo de estudantes (NISKIER, 2000, p.49).
\end{abstract}

A democratização da Educação a Distância pode ser justificada pelo avanço tecnológico e pela característica atemporal que a referida modalidade apresenta. A expressão "Ensino a Distância" foi amplamente utilizada, mas vêm sendo substituída por "Educação a Distância", por ser mais abrangente. A expressão "Ensino a Distância" dá mais ênfase ao papel do professor, deixando o aluno mais em segundo plano, enquanto que "Educação a Distância" permeia a ideia de aprendizagem compartilhada com envolvimento de professores e alunos de maneira igualitária (MORAN, 1994).

Com o avanço do desenvolvimento de serviços de tecnologias de alta velocidade, especialmente a internet, estão se estabelecendo uma nova infraestrutura nos meios de comunicação em todos os âmbitos, inclusive no educacional. Bouras et al. (2000) reafirma esse posicionamento ao tratar da inserção das TIC nos espaços escolares, pontuando que "a implementação de serviços em redes educacionais desenvolvidas com características de fidedignidade na transmissão de informação, manipulação de procedimentos educacionais e administração dos usuários", constituem um importante suporte para a comunicação entre professores e alunos.

As possibilidades e alternativas da EaD com uso de Tecnologias de Informação e de Comunicação, tornam-se evidentes os desafios e as dificuldades enfrentadas tanto por professores como por estudantes. Ferreira (2009) elenca algumas condições sem as quais a EaD se torna inoperante e ineficaz, como a disponibilidade de recursos técnicos em perfeitas condições de utilização; a disponibilidade de material de apoio no próprio ambiente de formação; e, a existência de um plano detalhado de execução concebido coletivamente pelos coordenadores e formadores, embora flexível. 
As políticas, de orientação e normatização de legislação, permitiram que muitas instituições de Ensino Superior (IES) criassem cursos de Educação Superior a distância em várias áreas. No entanto, apesar desse crescimento, não temos ainda um quadro detalhado das IES que estão oferecendo esse tipo de formação na área de Ciências, e a formação que está sendo oferecida a esses alunos.

Cada uma dessas ações do Estado procura organizar o setor e impedir, com uma série de novas exigências, que a livre concorrência acabe por desvirtuar sobremaneira o sentido da Educação a Distância. Seja qual for o tipo de observação que se queira fazer a todas essas iniciativas, o fato é que, apesar delas, o poder público ainda não discutiu seriamente a questão central que está implicada nessa expansão da Educação a Distância: a formação de professores.

Segundo Giolo (2008) o movimento inicial da Educação a Distância, o de proporcionar formação regular e continuada aos professores em exercício (os professores leigos), é repleto de mérito e, porque não dizer, de êxito. Não se pode falar o mesmo, entretanto, do que veio depois, quando os cursos de formação de professores passaram a disputar os alunos dos cursos presenciais, substituindo a sala de aula pela formação em trânsito, descolada dos espaços tradicionais de ensino e aprendizagem.

Ferreira (2009) aponta que as concepções das modalidades educacionais, incluindo a $\mathrm{EaD}$, acompanham tendências educacionais distintas, bem como atendem a objetivos diferentes e às demandas de formação de professores também diferentes, que vão desde os moldes tradicionais da EaD, quanto podem ser voltados para a reflexão, colaboração e a construção de conhecimentos.

Ou seja, nos dias que correm, dificilmente, algum debate sobre educação deixa de tocar na questão da qualidade (ou melhor, no problema da falta de qualidade). Esse tema, por sua vez, aparece sempre conectado com a atividade docente e, no debate, é comum ignorar o esforço que os cursos de licenciatura fizeram, nos últimos anos, para melhorar o seu desempenho, empreendendo um esforço constante contra adversidades de toda a ordem. De qualquer forma, valem as perguntas: $\mathrm{O}$ que significa ser um bom professor e como prepará-lo para as adversidades do contexto educacional?

Interpretamos que a formação do bom professor não se resume apenas ao conhecimento científico-pedagógico e ao conhecimento do conteúdo propriamente dito, por isso, compartilhamos das ideias de Alarcão (2003), nas quais a autora elenca alguns conhecimentos necessários à formação de um professor no sentido de prepará-lo para as adversidades do contexto educacional. Os conhecimentos por ela destacados são: conhecimento científico-pedagógico; conhecimento do conteúdo disciplinar; conhecimento pedagógico em geral; conhecimento do currículo; conhecimento do aluno; conhecimento dos contextos; conhecimento de si mesmo; e, conhecimento da sua filiação profissional.

Neste sentido, o parecer do Conselho Nacional de Educação, CNE/CP no 2/2015, que propõe a reformulação das licenciaturas destaca:

Há questões e problematizações relativas ao repertório de conhecimento dos professores em formação; ao tratamento de conteúdos e dos modos de gerar, difundir e avaliar conhecimento; às oportunidades para desenvolvimento cultural; às concepções de prática educacional; à pesquisa; às articulações entre etapas e modalidades da educação básica que não são consideradas em sua plenitude; à relação entre matrizes curriculares do processo formador e a 
base nacional comum e garantia de diversificação curricular, bem como dos sentidos do trabalho contemporâneo; às disputas sociais e políticas de que a educação e escola fazem parte; aos sentidos de diversidade e desigualdade. Por certo, há indicações de possiveis soluções, mas essas não constituem, ainda, uma política nacional de formação sob intenso e contínuo regime de colaboração entre os entes federados (BRASIL, 2015, p. 4).

O referido documento ainda traz à tona as discussões em torno da base comum nacional como fundamento para a formação de profissionais para a Educação Básica, que contemple todas as suas etapas (Educação Infantil, Ensino Fundamental e Ensino Médio) e modalidades (Educação de Jovens e Adultos, Educação Especial, Educação Profissional e Técnica de nível Médio, Educação Escolar Indígena, Educação do Campo, Educação Escolar Quilombola e Educação a Distância) (BRASIL, 2015).

Dentre as discussões apresentadas, verifica-se que a busca pela valorização profissional dos professores permeia por diversos aspectos, que vão desde os conhecimentos dos professores em formação até as distintas etapas e modalidades em que este profissional poderá atuar. Assim, tendo em vista que a EaD consiste em uma dessas modalidades elencadas no documento e a partir da sua iminência possibilitada pelo avanço tecnológico, consideramos importante compreender e discutir a EaD nos diferentes espaços de formação, seja inicial e/ou continuada.

Portanto, na busca por referenciais a respeito da EaD na formação inicial do professor de Química, delimitamos dois importantes eventos científicos da área de Ensino de Química, sendo um deles de nível estadual (CPEQUI) e o outro nacional (ENEQ), para realizar uma busca sobre as pesquisas que vem sendo desenvolvidas em torno da inserção de aspectos relativos a esta temática ao longo da formação inicial. Guimarães e Hayashi (2014) defendem a importância dos eventos científicos como espaços privilegiados para a comunicação da Ciência. Segundo as autoras os eventos científicos possuem diversas funções, dentre elas, a perspectiva da produção gerada que se tornam evidências para avaliar o desenvolvimento da área enfocada.

Em relação aos eventos selecionados, o Congresso Paranaense de Ensino de Química (CPEQUI) é um evento bianual que ocorre desde 2009, organizado pelas instituições paranaenses de Ensino Superior que possuem cursos de Licenciatura em Química. O objetivo é congregar professores, pesquisadores e estudantes da área para socializar e discutir ideias, produções, concepções e práticas. As áreas temáticas para a submissão de trabalhos no evento são: Ensino e aprendizagem (EAP); Formação de Professores (FP); Materiais Didáticos (MD); Linguagem e Cognição (LC); Experimentação no Ensino (EX); História, Filosofia e Sociologia da Ciência (HFS); Educação em espaços não formais e divulgação científica (EFD); Tecnologias da Informação e Comunicação (TIC); Educação ambiental (EA); Abordagem Ciência, Tecnologia e Sociedade (CTS); Currículo e Avaliação (CA); Educação Inclusiva (EI); Políticas Educacionais (PE); Diversidade, Multiculturalismo, Interculturalidade, Arte e Educação em Ciências (DMIAE) ${ }^{1}$.

Já o Encontro Nacional de Ensino de Química (ENEQ) é o maior e mais importante evento da comunidade de Ensino de Química do país. Também ocorre bianualmente, de maneira alternada ao CPEQUI e a sua primeira edição foi em 1982. Desde então já ocorreram 18 edições deste evento. $O$ evento tem reunido docentes universitários, professores da Educação Básica e alunos de vários níveis 
de ensino, desde o médio até a pós-graduação. A média de participantes nos últimos encontros tem sido de 2 mil inscritos e mais de mil trabalhos apresentados, estimulando a área de pesquisa em Ensino de Química e discussões de experiências de ensino e formação de professores de química. As áreas para a submissão de trabalhos são: Ciência, Tecnologia e Sociedade (CTS); Currículo e Avaliação (CA); Educação Ambiental (EA); Educação em espaços não-formais e divulgação Científica (EFD); Ensino e Aprendizagem (EAP); Experimentação no Ensino (EX); Formação de Professores (FP); História, Filosofia e Sociologia da Ciência (HFS); Inclusão e Políticas Educacionais (IP); Linguagem e Cognição (LC); Materiais Didáticos (MD); Tecnologias da Informação e Comunicação (TIC)².

A busca foi realizada dentre os anais destes eventos. Quanto ao CPEQUI foram verificados os trabalhos apresentados nas quatro edições já realizadas (2009 a 2015) E, com relação ao ENEQ foram verificados os trabalhos apresentados nas últimas cinco edições (2008 a 2016), período que se intercala às ocorrências do CPEQUI.

Assim, verificamos nos títulos, resumos e palavras-chave dos trabalhos constituintes dos anais, o aparecimento dos termos "Educação a Distância" e/ou "Ensino a Distância" ou ainda a sigla "EaD".

O Quadro 1, a seguir, ilustra os trabalhos encontrados para cada evento de acordo com a área de pesquisa.

Quadro 1 - Trabalhos apresentados no ENEQ e no CPEQUI no período de 2008 a 2016 que apresentam em suas discussões a temática Educação a Distância

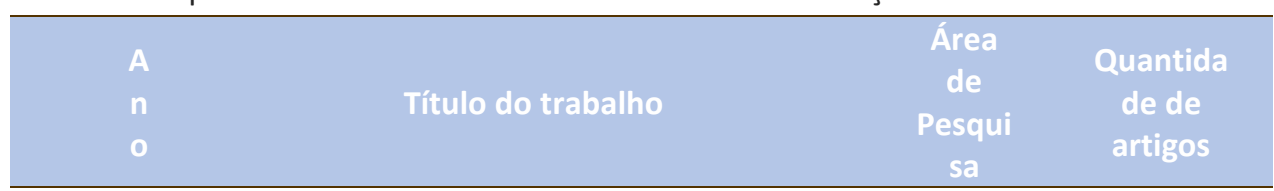
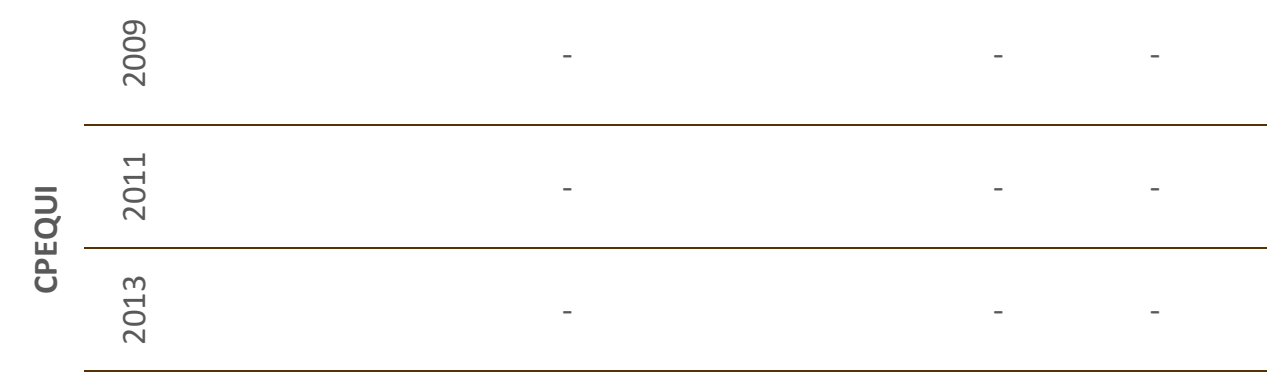

$\stackrel{n}{\circ}$

\begin{tabular}{|c|c|c|c|c|}
\hline \multirow{4}{*}{ 品 } & \multirow{2}{*}{$\stackrel{\infty}{\stackrel{一}{\nu}}$} & $\begin{array}{c}\text { Expectativas dos alunos recém-ingressados no } \\
\text { curso de Licenciatura em Química- modalidade a } \\
\text { distância }\end{array}$ & $\mathrm{FP}$ & 1 \\
\hline & & $\begin{array}{l}\text { A Química e os sentidos: um modelo para a } \\
\text { construção, acompanhamento e avaliação de } \\
\text { desenho instrucional para a EAD }\end{array}$ & $\mathrm{FP}$ & 1 \\
\hline & \multirow[b]{2}{*}{$\stackrel{\circ}{\circ}$} & $\begin{array}{l}\text { Um ambiente virtual de aprendizagem para a } \\
\text { formação e professores }\end{array}$ & TIC & 1 \\
\hline & & $\begin{array}{c}\text { O professor em formação na modalidade a } \\
\text { distância: algumas concepções importantes } \\
\text { encontradas }\end{array}$ & $\mathrm{FP}$ & 1 \\
\hline
\end{tabular}




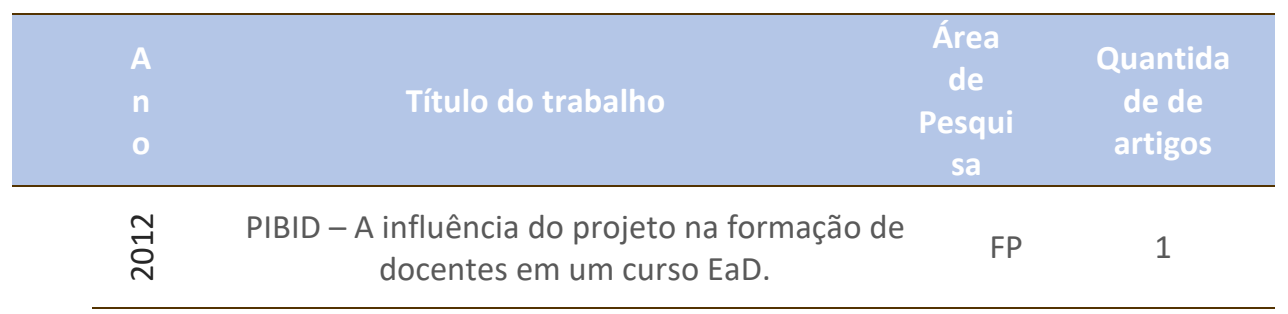

\begin{tabular}{|c|c|c|c|}
\hline$\stackrel{+}{\stackrel{\leftrightarrow}{\circ}}$ & ------- & ---- & ---- \\
\hline \multirow{4}{*}{$\stackrel{\bullet}{\stackrel{\ddots}{O}}$} & $\begin{array}{c}\text { Atividade orientadora de ensino na educação à } \\
\text { distância: potencialidades para a formação de } \\
\text { professores }\end{array}$ & FP & 1 \\
\hline & $\begin{array}{l}\text { Fotografia como ferramenta auxiliar de avaliação } \\
\text { no ensino de Química à distância }\end{array}$ & TIC & 1 \\
\hline & $\begin{array}{c}\text { Atividades práticas e EAD: material didático para } \\
\text { titulações demonstrativas a distância }\end{array}$ & MD & 1 \\
\hline & $\begin{array}{l}\text { Escrita de relatos de experiência na visão dos } \\
\text { estudantes da licenciatura em Química a distância }\end{array}$ & LC & 1 \\
\hline
\end{tabular}

Fonte: Autoria própria (2017).

Observa-se que em relação ao CPEQUI, do total de 335 trabalhos apresentados ao longo das quatro edições, não houve correspondência com nenhuma pesquisa publicada nos anais do evento referentes a algum aspecto da modalidade EaD. Apenas um trabalho da primeira edição do evento (I CEPEQ 2009) intitulado "Ensino de Química Contextualizado através da Mediação Tecnológica" apresentou o termo "Ensino a Distância" no decorrer do texto. Contudo, o foco da pesquisa estava voltado para a contextualização por meio da utilização de tecnologias do que propriamente os aspectos da EaD para ensinar Química.

Com relação ao ENEQ, no decorrer das últimas cinco edições do evento foram apresentados 5.659 trabalhos nas distintas áreas de pesquisa. Dessa totalidade, apenas 9 artigos referem-se a pesquisas voltadas a algum aspecto da EaD, sendo 5 delas com ênfase na formação de professores, 1 em materiais didáticos, 2 em TIC e 1 em linguagem e cognição. Portanto, percebemos que as discussões em torna da modalidade EaD na formação de professores é um pouco mais intensa, devido as necessidades formativas destes profissionais.

No entanto, é evidente a escassez de pesquisas relacionadas à EaD em todas as áreas de pesquisa, o que pode ser justificado pelo fato desta modalidade ter sido reconhecida pelo MEC como modalidade de ensino apenas no ano de 2005 com a regulamentação do artigo 80 da LDB. Ou ainda, pelo fato do documento que enfatiza a imposição de promover uma formação que atenda às necessidades de todas as modalidades de ensino ter sido publicado recentemente no ano de 2015.

Logo, mesmo com o crescimento do Ensino a Distância nas mais diversas instâncias educacionais, cursos e disciplinas, as pesquisas em torno desta temática são recentes e em número reduzido, o que nos leva a verificar a necessidade e importância de pesquisarmos a respeito das concepções que estudantes das licenciaturas, em específico do curso de Licenciatura em Química, possuem a respeito do ensino de Química na modalidade EaD, com a finalidade de tecermos reflexões e propostas para a formação dos futuros professores desta disciplina. 


\section{METODOLOGIA}

Esta pesquisa foi realizada durante a disciplina de Metodologia e Prática do Ensino de Química 4 (MPEQ 4) em uma turma composta por 5 estudantes, do 8응 período do curso de Licenciatura em Química de uma Universidade Federal localizada na cidade de Londrina - PR.

No decorrer desta disciplina, com duração de um semestre, uma das unidades trabalhadas em sala de aula são as Tecnologias de Informação e de Comunicação na Educação. No decorrer do estudo sobre tecnologias, os estudantes produziram um webquest utilizando algum conteúdo químico de sua escolha. Durante as discussões sobre tecnologias no Ensino, surgiu o tema da Educação a Distância, visto o desconhecimento e divergências sobre o tema, a professora abriu espaço para trabalhá-lo durante 4 aulas.

Antes de iniciar a abordagem sobre Educação a Distância, a professora solicitou aos estudantes que respondessem a um questionário a respeito do tema. Esse questionário, composto por 4 questões, culminou na coleta dos dados dessa pesquisa:

1) Qual a sua opinião sobre a EaD?

2) Quais as perspectivas futuras para a EaD?

3) É possível ensinar Química a distância? Como ensinar Química utilizando a $\mathrm{EaD}$ (ensino médio e superior)? Básica.

4) Proponha uma atividade em que você possa utilizar EaD na Educação

Para a análise das respostas, optamos pelos procedimentos e características da análise de conteúdo, metodologia de pesquisa utilizada para descrever e interpretar o conteúdo de toda classe de documentos e textos (MORAES, 1999). Nos parágrafos seguintes estão descritas as etapas da análise de conteúdo segundo Moraes (1999), bem como as utilizamos para a análise dos dados desta investigação.

De acordo com Moraes (1999) esta abordagem metodológica constitui-se bem mais do que uma simples técnica de análise de dados, uma vez que apresenta características e possibilidades próprias, desenvolvida em cinco etapas: 1) preparação das informações; 2) unitarização; 3) categorização; 4) descrição e 5) interpretação.

A fase de preparação é dividida em duas etapas: a primeira consiste em identificar as diferentes amostras de informação a serem analisadas. Por ser a Educação a Distância o cerne da atividade proposta, procuramos identificar neste estudo as concepções dos estudantes sobre as implicações e perspectivas da mesma. Por isso, na fase de preparação escolhemos as respostas dos 5 estudantes que responderam ao questionário em sua totalidade para a análise dos dados desta pesquisa.

A segunda etapa da preparação consiste em estabelecer um código que possibilite identificar cada elemento, portanto foi adotada para as falas dos estudantes a codificação E1, E2..., E5, representando cada estudante. 
O processo de unitarização consiste em um processo de desmontagem dos textos, por meio do qual se dá a definição das unidades de análise. Estas "unidades podem ser tanto as palavras, frases, temas ou mesmo os documentos em sua forma integral" (MORAES, 1999, p. 16). Após relermos as respostas à questão escolhida, optamos por mantê-las em sua forma íntegra buscando não descontextualizar as ideias que estas unidades expressam.

A categorização consiste em agrupar os dados considerando a parte comum existente entre eles, ou seja, é uma operação de classificação dos elementos de uma mensagem seguindo determinados critérios. Estes critérios podem ser previamente estabelecidos (a priori) ou definidos no processo (a posteriori). Neste estudo as categorias foram definidas a posteriori, de acordo com a leitura das respostas dos estudantes.

$\mathrm{Na}$ fase de descrição, são apresentadas as categorias, as quais expressam os significados captados e intuídos nas mensagens analisadas. A partir da interpretação das respostas dos estudantes, estabelecemos as categorias de análise, as quais codificamos como $\mathrm{C} 1, \mathrm{C} 2 \ldots$, acompanhado da questão a que ela se refere, por exemplo C1.1 - apresenta as respostas dos estudantes que avaliam a Educação a Distância como uma modalidade válida e necessária devido a sua atemporalidade.

Por fim, realizamos a interpretação do conteúdo, etapa em que é importante procurar ir além da descrição, buscando atingir uma compreensão mais aprofundada do conteúdo das mensagens (MORAES, 1999).

\section{RESULTADOS E DISCUSSÃO}

Após realizarmos inúmeras leituras das respostas dos 5 estudantes, acomodamos em 3 categorias a questão 1, C1.1, C1.2 e C1.3. Já as demais questões foram agrupadas em duas categorias cada uma elas, como é possível observar no Quadro 2. Abaixo, são apresentadas as 9 categorias, agrupadas de acordo com a questão envolvida, a ocorrência de respostas e um exemplo que ilustra cada categoria.

A partir da leitura e construção das categorias descritas na Tabela 1, pudemos identificar que a questão 1 , sobre a concepção de $\mathrm{EaD}$, foi a mais dispersa, com a presença de três categorias. Um estudante refuta a EaD colocando como empecilho a falta de autonomia do estudante. A maioria dos entrevistados (3) não possui uma posição definida, demonstram desconhecimento e apresentam ambiguidades, prós e contras sobre a mesma.

Ferreira (2009) verificou que existem muitas controvérsias a respeito dessa temática, envolvendo sua conceituação, terminologia e até mesmo incoerências entre abordagens educacionais. Desta forma, não é incomum as pessoas não conseguirem determinar ou se posicionar a respeito do tema. 
Quadro 2 - Categorias estabelecidas a partir da análise das respostas dos estudantes ao questionário e o número de ocorrências em cada uma delas

\begin{tabular}{|c|c|c|c|c|}
\hline के & $\begin{array}{l}\frac{\pi}{2} \\
\frac{0}{0} \\
\frac{0}{9} \\
\frac{10}{80}\end{array}$ & $\begin{array}{c}\text { Descrição das } \\
\text { categorias }\end{array}$ & 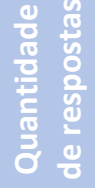 & Exemplos \\
\hline \multirow{3}{*}{ 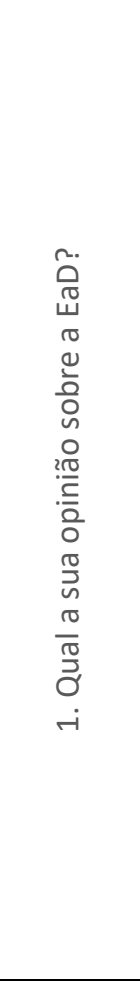 } & C1.1 & $\begin{array}{c}\text { Refere-se as respostas que } \\
\text { avaliam a EaD como uma } \\
\text { modalidade válida e } \\
\text { necessária devido a sua } \\
\text { atemporalidade }\end{array}$ & 1 & $\begin{array}{l}\text { "Possibilita diminuir a distância } \\
\text { entre a universidade e a } \\
\text { população e sendo flexível em } \\
\text { relação ao tempo disponível que } \\
\text { a pessoa tem para estudar" (E1) }\end{array}$ \\
\hline & C2.1 & $\begin{array}{c}\text { Refere-se as respostas que } \\
\text { tratam a EaD com seus } \\
\text { prós e contras }\end{array}$ & 3 & $\begin{array}{c}\text { "Para mim, é bastante } \\
\text { complicado dizer minha opinião } \\
\text { sobre o EaD, pois acho que } \\
\text { existem pontos positivos e } \\
\text { negativos, e esses "pontos" vão } \\
\text { depender de alguns fatores, } \\
\text { como o instituto de ensino que } \\
\text { está oferecendo o curso, o aluno } \\
\text { que está cursando, o material, } \\
\text { entre outros" (E3) }\end{array}$ \\
\hline & C3.1 & $\begin{array}{c}\text { Respostas relacionadas a } \\
\text { um posicionamento } \\
\text { contrário a EaD }\end{array}$ & 1 & $\begin{array}{l}\text { “Eu não sou a favor da Educação } \\
\text { a Distância, a cultura dos } \\
\text { brasileiros ainda não é a de } \\
\text { estudar sozinho e aprender a se } \\
\text { virar em relação a suas dúvidas. } \\
\text { Não consigo ver qualidade ou } \\
\text { ponto positivo em relação a EaD" } \\
\text { (E4) }\end{array}$ \\
\hline \multirow{2}{*}{ 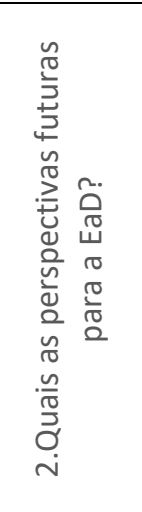 } & C1.2 & $\begin{array}{l}\text { Respostas relacionadas ao } \\
\text { progresso e aumento da } \\
\text { EaD devido às tecnologias }\end{array}$ & 4 & $\begin{array}{c}\text { "A tendência é o EaD continuar } \\
\text { crescendo, ainda mais que a } \\
\text { tecnologia vem avançando cada } \\
\text { vez mais" (E2) }\end{array}$ \\
\hline & $\mathrm{C} 2.2$ & $\begin{array}{l}\text { Respostas relacionadas à } \\
\text { qualidade de ensino na } \\
\text { EaD e ao público da } \\
\text { mesma }\end{array}$ & 1 & $\begin{array}{l}\text { “A falta de leitura está muito } \\
\text { presenta na sociedade brasileira } \\
\text { em geral, então enquanto não } \\
\text { suprir esse problema cultural, } \\
\text { Educação a Distância com } \\
\text { eficiência é para aqueles poucos } \\
\text { que se comprometem e estudam } \\
\text { como vontade" (E5) }\end{array}$ \\
\hline \multirow{2}{*}{ 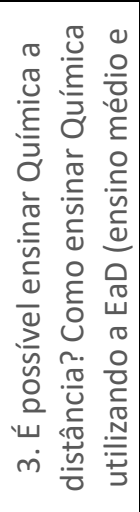 } & C1.3 & $\begin{array}{c}\text { Respostas relacionadas a } \\
\text { possibilidade de ensinar/ } \\
\text { aprender Química na EaD, } \\
\text { desde que o mesmo seja } \\
\text { autônomo }\end{array}$ & 2 & $\begin{array}{l}\text { “Sim, acredito ser possível } \\
\text { ensinar Química a distância, no } \\
\text { entanto, o discente tem que ter a } \\
\text { capacidade de conseguir estudar } \\
\text { sozinho, recorrer aos meios } \\
\text { disponíveis sozinho para } \\
\text { conseguir sanar as suas dúvidas. } \\
\text { Ter uma autonomia" (E1) }\end{array}$ \\
\hline & $\mathrm{C} 2.3$ & $\begin{array}{c}\text { Respostas relacionadas a } \\
\text { impossibilidade de } \\
\text { ensinar/aprender Química } \\
\text { na EaD } \\
\end{array}$ & 3 & $\begin{array}{l}\text { "Sim, é possível. Acho que não se } \\
\text { pode abrir mão do trabalho } \\
\text { presencial, pois é essencial que os } \\
\text { alunos tenham o apoio de um }\end{array}$ \\
\hline
\end{tabular}




\begin{tabular}{|c|c|c|c|c|}
\hline$\frac{y}{\frac{1}{2}}$ & $\frac{10}{2}$ & $\begin{array}{c}\text { Descrição das } \\
\text { categorias }\end{array}$ & 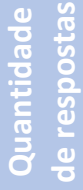 & Exemplos \\
\hline & & & & $\begin{array}{l}\text { professor para eventuais dúvidas } \\
\text { que surgirem. Além disso, } \\
\text { considero muito importante } \\
\text { discussões em sala, pois acho que } \\
\text { enriquece muito as aulas" (E2) }\end{array}$ \\
\hline 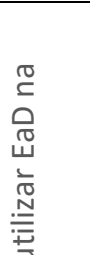 & C1.4 & $\begin{array}{l}\text { Refere-se as repostas que } \\
\text { mencionam a Webquest } \\
\text { como uma proposta de } \\
\text { ensino de Química na EaD }\end{array}$ & 3 & $\begin{array}{l}\text { "A webquest é uma proposta de } \\
\text { atividade EaD, onde permite ao } \\
\text { aluno que ele guie seu } \\
\text { conhecimento, e onde pode ser } \\
\text { usado vídeos, imagens, textos de } \\
\text { apoio e etc." (E3) }\end{array}$ \\
\hline 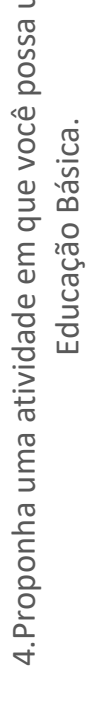 & C2.4 & $\begin{array}{c}\text { Respostas relacionadas a } \\
\text { recursos e ferramentas } \\
\text { para o ensino de Química } \\
\text { na EaD }\end{array}$ & 2 & $\begin{array}{l}\text { "Se hipoteticamente todos os } \\
\text { alunos tivessem acesso à internet } \\
\text { e computadores em suas casas, } \\
\text { daria para fazer listas de } \\
\text { exercícios para que os alunos } \\
\text { entrassem e resolvessem, o } \\
\text { professor de cálculo do curso de } \\
\text { Química da UTFPR utilizava o } \\
\text { MoODLE para enviar listas de } \\
\text { exercícios, fazer uma avaliação } \\
\text { diagnóstica, sugestões de vídeo } \\
\text { aula, as notas das avaliações e } \\
\text { trabalhos, foi uma experiência } \\
\text { boa que tivemos em relação ao } \\
\text { uso deste programa, daria para } \\
\text { aplicar para o ensino médio } \\
\text { também" (E4) }\end{array}$ \\
\hline
\end{tabular}

Fonte: Autoria própria (2017).

Apenas um estudante considera a EaD relevante sem restrições. Este estudante, além de cursar a Licenciatura em Química presencialmente, cursa Matemática na modalidade a distância. Logo, possui argumentos e conhece melhor o sistema da EaD do que os demais.

Com relação às perspectivas da EaD, apesar de não possuírem um posicionamento argumentativo sobre a mesma, a maioria dos estudantes acreditam na expansão da modalidade, atribuindo principalmente a tecnologia que viabilizou esse progresso.

Freitas e Sousa (2013) corroboram com essa ideia, ao discutirem que diante dos avanços tecnológicos, esta modalidade de educação, que exige a utilização de tecnologias para que o processo de ensino-aprendizagem ocorra, expande-se nos diversos níveis de ensino, em particular no Ensino Superior.

A categoria C2.2 remete ao estudante que responde à questão em termos de qualidade da EaD no que diz respeito as perspectivas futuras. O estudante argumenta que nem todos os alunos estão aptos para estudar nessa modalidade, e que o empenho do aluno é o fator determinante de uma educação de qualidade. 
Embora se enfatize fortemente a necessidade de valorização da construção autônoma do aluno, dependente da vontade deste estudar, pesquisar e produzir de forma independente e disciplinada, compreende-se que esta modalidade educacional se fortalece, por meio de múltiplas atividades, através da aprendizagem colaborativa, com a troca de informações entre alunos (MAIA e MEIRELLES, 2002). Logo, a inserção de um aluno em curso EaD possibilita por meio da aprendizagem colaborativa e autônoma que ele tenha um ensino de qualidade e se transforme em um excelente profissional, com as mesmas condições de um aluno da modalidade presencial.

A questão 3 questionava os estudantes a respeito da possibilidade de ensinar Química a distância. As respostas dos 5 estudantes resultaram em duas categorias: a C1.3 se refere às falas dos estudantes que consideram possível ensinar Química a distância. Para tanto, o argumento utilizado pelo E1, como apresentado na tabela 1 é de que para conseguirem estudar nessa modalidade os estudantes devem ser autônomos. Mas o que é essa autonomia? É uma característica intrínseca do ser humano ou pode ser desenvolvida durante a sua formação? Serafini (2012) esclarece essa posição:

\begin{abstract}
A autonomia não depende somente do aluno e de suas características individuais. Ela se mostra muito mais complexa, a autonomia depende também da metodologia adotada, do material didático e do professor e das tecnologias de comunicação e informação empregadas. Cabe, portanto, uma breve reflexão sobre o papel que cada um desses elementos exerce no processo de ensino e de aprendizagem, e de que forma contribuem para que a autonomia possa ser viabilizada (SERAFINI, 2012, p. 74).
\end{abstract}

Fica evidente que essa autonomia é interdependente da estruturação do curso, dos docentes, da metodologia e não apenas do estudante. Logo, a justificativa de que apenas estudantes "autônomos" podem cursar algum curso a distância não é relevante.

Já as respostas da categoria C1.3 remetem a impossibilidade de ensinar Química totalmente a distância. Os três estudantes alocados nesta categoria argumentam a necessidade de um professor para sanar as dúvidas dos alunos. Contudo, eles demonstram não ter base teórica sobre a Educação a Distância, uma vez que na EaD, além do professor, há o professor-tutor para auxiliarem os estudantes no processo de ensino-aprendizagem. Na EaD, além do papel do professor e aluno, há também o do tutor o qual auxilia o professor no exercício de seu trabalho como docente (KONRATH, TAROUCO, BEHAR, 2009).

Moulin et al. (2004 apud Ferreira, 2009) reitera que o tutor não ensina no sentido convencional da palavra, como também não dá aulas nem produz os materiais didáticos, mas ele é o responsável por estabelecer contato com o estudante por meio de uma relação pessoal e dialógica.

Já na questão 4, em que os estudantes deveriam propor uma atividade para ensinar Química a distância, todos os estudantes citaram algum recurso tecnológico que utilizariam, mas não descreveram uma atividade com algum conteúdo químico. A maior parte dos estudantes (3) alocados na categoria C4.1 citaram apenas a webquest como recurso tecnológico. Já os dois estudantes alocados na categoria C4.2 falaram sobre outros recursos, como ilustrado na Tabela 1, em que E4 cita o moodle. A maior incidência de falas na categoria C4.1 pode ser explicada pelo fato dos estudantes terem estudado e confeccionado uma 
webquest no início da unidade sobre Tecnologias na Educação, tema anterior ao estudo de Educação a Distância, que gerou a discussão e iniciou a introdução.

\section{CONSIDERAÇÕES FINAIS}

Foi possível observar que os estudantes em suas respostas, em diversos momentos admitem desconhecer e não possuir embasamento para falar sobre a Educação a Distância. Houveram estudantes que refutaram a $\mathrm{EaD}$, aqueles que acreditam e os que se mostram ambíguos quanto à sua contribuição. Contudo, apesar de não a conhecerem de maneira contundente, percebem que a perspectiva é que a Educação a Distância cresça e amplie sua área de atuação, devido a flexibilidade e atemporalidade.

Quando questionados sobre a possibilidade de utilizar a EaD nas aulas de Química, os estudantes, em sua maioria, mencionaram que é possível ensinar/aprender Química parcialmente a distância, e não literalmente a distância, utilizando como argumento a necessidade de um professor para auxiliá-los. Neste ponto percebemos mais uma vez que os estudantes apresentam um grande desconhecimento desta modalidade de ensino, uma vez que apesar das aulas serem disponibilizadas por meio de vídeo-aulas via internet, os alunos têm a opção de utilizar os mais diversos meios de comunicação como telefone, e-mail, videoconferência, entre outros, para se comunicar com o professor-tutor para sanar dúvidas.

Por conseguinte, os estudantes investigados ainda demonstraram não conhecerem os meios de comunicação que podem ser utilizados para a realização das atividades na $\mathrm{EaD}$, remetendo como resposta apenas a atividade que por eles fora realizada na disciplina, a webquest. Por não a conhecerem e não estarem familiarizados com a EaD não compreendem as implicações da mesma, assim como não apontaram questionamentos relevantes sobre a abordagem no Ensino de Química, por exemplo as atividades experimentais.

É importante ressaltar que durante a graduação, foi o primeiro momento em que tiveram a oportunidade de debater o tema, que surgiu durante uma aula sobre TIC. Dessa forma, compreendemos que é importante que este tema seja debatido dentro da formação inicial docente, uma vez que se trata de uma modalidade de ensino com a qual esses futuros docentes irão se deparar durante a sua prática, visto a expansão das tecnologias e a própria EaD.

A educação pede mudanças que viabilizem um ensino de qualidade, o que torna fundamental aperfeiçoar a formação tanto de professores atuantes como a formação inicial, para atender aos anseios da modificação das demandas sociais e educacionais para contribuir na formação da cidadania. Além disso, trabalhar a Educação a Distância nas disciplinas de prática de ensino, conceitualmente e com atividades práticas, fornece bases teóricas para eles discutirem e serem capazes de realizar atividades e/ou elaborarem atividades e materiais didáticos nessa perspectiva. 


\title{
Perceptions of students in Chemistry at Distance Education: reflections and proposals
}

\begin{abstract}
The paper herein aims to identify the perceptions of students of the graduation course in Chemistry at Distance Education (ODL) and to explore them attempting to seek for training proposals that offer subsidies for future professors to work on this modality. The data has been collected through a questionnaire composed of 4 questions, answered by 5 students from the 8th period. The answers were analyzed and interpreted based on the Content Analysis, proposed by Moraes (1999). The results showed that these students, in the end of their graduation degree, presented divergent answers regarding the possibilities of the ODL, demonstrating a high index of ignorance about this modality of education. In addition, most students mention that teaching on this modality only progressed due to the technological evolution that has been taking place; however, they recognize the limitations of the ODL to teach Chemistry, due to the difficulty that the students present concerning this subject. We advocate on the importance of working on this topic in initial qualification so that students can theoretically base themselves on the possibilities of ODL. Moreover integrating the subject matter of the subjects of Teaching Practice, proposing to students the development of activities based on this modality.
\end{abstract}

KEYWORDS: Distance Education. Initial qualification. Chemistry. Textual analysis. 
NOTAS

${ }^{1}$ Informações disponíveis no atual site do evento (CPEQUI, 2017). Disponível em: https://contato5cpequi.wixsite.com/5cpequi.

${ }^{2}$ Informações disponíveis estão disponíveis no site do último evento realizado (ENEQ, 2016). Disponível em: http://www.eneq2016.ufsc.br/. 


\section{REFERÊNCIAS}

ALARCÃO, I. Professores reflexivos em uma escola reflexiva. 2 ed. São Paulo, SP: Cortez, 2003.

BARBOSA, A. P. L. A ressignificação da Educação a Distância no ensino superior do Brasil e formação de professores de Ciências e Matemática. 2010. 284 f. Dissertação (Mestrado em Ensino de Ciências) - Instituto de Química da Universidade de São Paulo, São Paulo, 2010. Disponível em:

$<$ http://www.teses.usp.br/teses/disponiveis/81/81132/tde-13052013092919/pt-br.php>. Acesso em: 20 jan. 2017.

BENAKOUCHE, T. Educação a Distância (EAD): Uma solução ou um problema? In: ENCONTRO ANUAL DA ANPOCS, 24, 2000, Petrópolis - RJ. Anais... Petrópolis-RJ, 2000. Disponível em: <http://www.anpocs.com/index.php/encontros/papers/24encontro-anual-da-anpocs/gt-22/gt02-17/4728-tbenakouche-educacao/file>. Acesso em: 20 abr. 2017.

BOURAS, C.; GKAMAS, A.; TSIATSOS, T. Network-Based Distributed Learning Environment. WebNet Journal, v. 2, n. 3, p. 177-189, 2000.

BRASIL. Lei no 9.394 de 20 de dezembro de 1996. Estabelece as diretrizes e bases da educação nacional. Diário Oficial da União, Brasília, 20 jul. 1996. Disponível em: <http://www. planalto.gov.br/ccivil 03/LEIS/L9394.htm>. Acesso em: 21 abr. 2017.

BRASIL. Decreto no 5.622, de 19 de dezembro de 2005. Regulamenta o art. 80 da Lei no 9.394, de 20 de dezembro de 1996, que estabelece as diretrizes e bases da educação nacional. Diário Oficial da União, Brasília, 19 dez. 2005. Disponível em: $<$ http://www.planalto.gov.br/ccivil 03/ ato2004-

2006/2005/decreto/d5622.htm>. Acesso em 21 abr. de 2017.

BRASIL. Resolução CNE/CP 2/2015, de 01 de julho de 2015. Define as Diretrizes Curriculares Nacionais para a formação inicial em nível superior (cursos de licenciatura, cursos de formação pedagógica para graduados e cursos de segunda licenciatura) e para a formação continuada. Diário Oficial da União, Brasília, 2 jul. 2015. Disponível em:

$<$ http://portal.mec.gov.br/index.php?option=com docman\&view=download\&ali as=17719-res-cne-cp-002-03072015\&category slug=julho-2015pdf\&ltemid=30192>. Acesso em: 21 abr. 2017.

FERREIRA, Z. M. Prática pedagógica do professor-tutor em Educação a Distância no curso "Veredas - formação superior de professores. 2009. 312p. Tese (Pósgraduação em Educação) - Faculdade de Educação. Universidade de São Paulo (USP), São Paulo, 2009. Disponível em: 
$<$ http://www.teses.usp.br/teses/disponiveis/48/48134/tde-03092009140200/pt-br.php>. Acesso em: 20 jan. 2017.

FREITAS, L. G.; SOUSA, C. A. M. Mediação pedagógica na Educação a Distância: as pesquisas brasileiras. Linhas Críticas, v.19, n.40, p. 523-542, 2013. Disponível em: <http://periodicos.unb.br/index.php/linhascriticas/article/view/12454/8677>. Acesso em: 20 abr. 2017.

GARCIA, P. S.; GOUW, A. M. S. Educação superior a distância: políticas, tendências da formação de professores de ciências. In: ENCONTRO NACIONAL DE PESQUISA EM EDUCAÇÃO EM CIÊNCIAS, 7, 2009, Florianópolis - SC. Anais... FlorianópolisSC, 2009. Disponível em: <http://posgrad.fae.ufmg.br/posgrad/viienpec/pdfs/1066.pdf>. Acesso em: 15 jan. 2017.

GUIMARÃES, V. A. L.; HAYASHI, M. C. P. I. Os Eventos Científicos: espaços privilegiados para a comunicação da Ciência. Comunicologia: Revista de Comunicação e Epistemologia da Universidade Católica de Brasília. v.7, n. 2, p. 204 - 229, 2014. Disponível em: <https://portalrevistas.ucb.br/index.php/RCEUCB/article/viewFile/5656/3745> Acesso em: 26 Abr. 2017.

GIOLO, J. A Educação a Distância e a formação de professores. Educação \& Sociedade, v. 29, n. 105, p. 1211-1234, 2008. Disponível em: <http://www.cedes.unicamp.br>. Acesso em: 25 out. 2016.

KONRATH, M. L. P.; TAROUCO, L. M.; BEHAR, P. A. Competências: desafios para alunos, tutores e professores da EaD. Novas Tecnologias na Educação, v. 7 n. 1, 2009. Disponível em:

<http://seer.ufrgs.br/index.php/renote/article/view/13912/7819>. Acesso em: 15 jan. 2017.

MAIA, M. C., MEIRELLES, F. S. Educação a Distância: o caso da Open University. RAE Eletrônica, v. 1, n. 1, p. 1-15, 2002. Disponível em: $<$ http://rae.fgv.br/sites/rae.fgv.br/files/artigos/10.1590 S167656482002000100004.pdf>. Acesso em: 20 jan. 2017.

MORAN, J. O que é educação a distância. Disponível em: <http://www.eca.usp.br/prof/moran/dist.htm>. Acesso em 20 Jan. 2017.

MORAES, R. Análise de conteúdo. Revista Educação. v. 22, n. 37, p. 7-32, 1999. Disponível em: $<$ http://cliente.argo.com.br/ mgos/analise de conteudo moraes.html>. Acesso em: 22 jan. 2017. 
NISKIER, A. Educação à distância, a tecnologia da esperança: políticas e estratégias para a implantação de um sistema nacional de educação aberta e à distância. São Paulo: Loyola, 2000.

PAULIN, J. F. V., MISKULIN, R. G. S. Educação a Distância Online e Formação de Professores: práticas de pesquisas em Educação Matemática no estado de São Paulo. Bolema. v. 29, n. 53, p. 1084-1114, 2015. Disponível em: <http://dx.doi.org/10.1590/1980-4415v29n53a15>

SERAFINI, A. M. S. A autonomia do aluno no contexto da Educação a Distância. Educação em foco, v. 17, n. 2, p. 61-82, 2012. Disponível em: <http://www.ufjf.br/revistaedufoco/files/2013/05/artigo-031.pdf>. Acesso em: 22 jan. 2017.

Recebido: 29 mai. 2017

Aprovado: 21 jul. 2017

DOI: 10.3895 /actio.v2n1.6740

Como citar:

ASSAI, N. D. de S.; ARRIGO, V.; ARRUDA, S. de M. Percepções de licenciandos em Química sobre a

Educação a Distância: reflexões e propostas. ACTIO, Curitiba, v. 2, n. 1, p. 80-97, jan./jul. 2017. Disponível

em: <https://periodicos.utfpr.edu.br/actio>. Acesso em: XXX.

Correspondência:

Natany Dayani de Souza Assai

Rua Madre Henriqueta Dominici, 750. Bloco 10, Apartamento 03, Londrina, Paraná, Brasil.

CEP: 86041-346

Direito autoral: Este artigo está licenciado sob os termos da Licença CreativeCommons-Atribuição 4.0

Internacional.

(c) (i) 